\title{
Relationship between Math Anxiety and Perception of the Utility of Geometry in Primary Education in Prospective Teachers
}

\author{
David Gutiérrez-Rubio ${ }^{1, *}$, Carmen León-Mantero ${ }^{1}$, Alexander Maz-Machado ${ }^{1}$, \\ María José Madrid-Martín² \\ ${ }^{1}$ Department of Mathematics, Faculty of Education, University of Córdoba, Spain \\ ${ }^{2}$ Pontifical University of Salamanca, Spain
}

Received September 26, 2019; Revised January 16, 2020; Accepted February 7, 2020

Copyright $\bigcirc 2020$ by authors, all rights reserved. Authors agree that this article remains permanently open access under the terms of the Creative Commons Attribution License 4.0 International License

\begin{abstract}
Math Anxiety not only plays an important role in the academic performance of students but also has a significant influence on the methodology adopted by teachers. In this study, we examine the relationship between the levels of Math Anxiety of a group of prospective teachers and their opinions about the importance of Geometry in Primary Education. Abbreviated Math Anxiety Scale (AMAS) was applied to 152 students of the Primary Education Degree, along with open-ended questions on their opinions about the role of Geometry in Primary School. An internal consistency check and a factorial analysis were performed on AMAS data to obtain factors Math Learning Anxiety (MLE) and Math Evaluation Anxiety (MEA). The responses from the open-ended questions were categorized and classified into procedural or relational reasons. Results indicate a biased conception about what Geometry teaching should be. Procedural reasons are related to higher levels of Math Anxiety, being the MLE factor more correlated than MEA. Conversely, relational reasons are related to lower levels of such anxiety. Not all the reasons were correlated at the same level, and no differences between genders were observed in the reasons alleged. Results suggest that emotional factors in prospective teachers should be taken into account as they can induce a bias in their future didactic strategies.
\end{abstract}

Keywords Teacher Training, Math Anxiety, Math Perception, Geometry

\section{Introduction}

The National Council of Teachers of Mathematics [1] emphasizes the importance of Geometry in Primary
Education, as it is the natural situation for the development of reasoning and can be an important tool in problem solving. This field, together with Algebra, should cover most of the time during middle Primary Education classes.

The Spanish law [2] defines as one of the objectives of Primary Education to introduce children into problem solving using geometric reasoning in order to be able to apply in everyday problems.

However, studies such as those of [3] show that, despite the efforts made by school institutions and researchers to present new proposals, methodologies and resources on the teaching of Geometry, students who access the education degrees, face their initial formation with lack of knowledge of Geometry and without knowing how to learn from the constructivist culture.

For example, a study carried out by [4] on conceptions about Geometry teaching from prospective teachers showed a procedural way of thinking, as they perceived the Geometry as something difficult, where problem solving was understood as identifying it from a list of standard problems in order to apply the right formula. These conceptions were strongly determined by their past experiences as students.

When Mathematics is being taught, the affective domain of students and professors plays an important role in their predisposition towards the subject. Therefore, it makes sense to analyze them in detail [5-9].

One important variable in the affective domain is the Math Anxiety. [10] defines it as the feeling of tension that interferes with the student when working on calculating or solving problems in academic situations or arising in everyday life. In this sense [11] define the anxiety towards Mathematics in relation to the physical symptoms of nervousness that arise when working the subject. 
Anxiety towards Mathematics has been widely analysed in students. PISA 2012 report [12] points out that anxiety in high school students influences performance in Mathematics class adversely, as the student diverts part of his attention to worrying about having to solve mathematical problems. More specifically, Math Anxiety can be more correlated with achievements in math problems involving relations than ones involving only numbers or measures [13].

Works such as that of [14] showed that attitudes towards Mathematics in primary and secondary students are those that determine the degree of anxiety towards the subject and, therefore, when better attitudes are showed, lower levels of anxiety are shown. [15, 16] studied the effect that Mathematical Anxiety has on performance and self-concept in Mathematics. [17] show significant differences in anxiety between men and women, with women being the most anxious when faced with mathematical tasks.

The effect of mathematical anxiety on teachers has also been studied. Thus, for example, according to a study conducted in primary schools in the U.S., Mathematical Anxiety of female teachers affects the perception of female students, not so to male students [18].

In a similar study by [19], although no evidence was found that the anxiety of teachers has an impact in the anxiety of students, it was obtained evidence that teachers with higher levels of Mathematical Anxiety tended to use a more traditional methodology with a more procedural approach, greater use of lectures, less use of games, or less focus on problem solving. This relationship between higher levels of anxiety and a procedural approach to Mathematics was also investigated in students by authors such as [20, 21].

\section{Materials and Methods}

The objective of this study is to analyze, identify and categorize the perceptions of the future teachers on the importance of teaching Geometry in Primary Education, and to relate it to the levels of Mathematical Anxiety they present.

An exploratory study was proposed. We passed an anonymous survey at the beginning of the course to 152 students of the third year of the Primary Education Degree of the University of Córdoba, Spain. The data was collected right at the start of a subject about teaching Geometry. These students were previously instructed in a general mathematics subject in the first year, which included basic aspects of plane and spatial Geometry. In the second year they were taught a more specific subject in didactics of numbers and measure, so they had some knowledge about teaching aspects of Mathematics. The age of $95 \%$ participants were in the range of 20-25 years, with the remaining 5\% were between 26 and 50 years. The percentage of male/female participants was $26,5 \%$ and $73,5 \%$ respectively.
The survey consisted, together with basic demographic questions (gender, age) and an open question: "In four or five lines explain why it is important to study Geometry in Primary Education" along with the abbreviated mathematical anxiety test AMAS [22]. Such test consists of 9 questions about situations related to mathematics which could potentially cause anxiety and a Likert scale where the participants describe their degree of anxiety in such situation. The two factors that can be extracted, Math Learning Anxiety (MLA) and Math Evaluation Anxiety (MEA) were considered [22].

Subsequently, software ATLAS.TI was used to encode the answers obtained in the open question. The codes obtained were classified in families and the relationship between them was studied, as the levels of Math Anxiety of participants, using the software SPSS version 21 to perform the quantitative analysis.

\section{Results}

\subsection{Justifications of Geometry in Primary Education}

From the answers obtained from the open questions, and using content analysis, 8 labels were defined, which were grouped into 2 categories, that is, those which allude to procedural reasons and those that allude to relational ones, plus the label "I think it is not important" that would not fit into any category. In this sense, we used the definitions given by [23], that is, the procedural reasons refer to the student being able to perform a determined procedure, and relational ones refer to the development of skills that Geometry can bring to them. Table 1 shows labels used together with their description, and frequency of occurrence.

Table 1. Categories of responses with frequency of occurrence

\begin{tabular}{|c|c|c|}
\hline \multicolumn{3}{|c|}{ Procedural reasons } \\
\hline Label & Description & Occurrence \\
\hline $\begin{array}{l}\text { Geometrical } \\
\text { figures }\end{array}$ & $\begin{array}{l}\text { It is important that children know } \\
\text { how to identify geometric figures. }\end{array}$ & $40,13 \%$ \\
\hline Magnitudes & $\begin{array}{l}\text { It is important that children know } \\
\text { how to calculate magnitudes } \\
\text { (lengths, areas and volumes) }\end{array}$ & $19,08 \%$ \\
\hline \multicolumn{3}{|c|}{ Relational reasons } \\
\hline Label & Description & Occurrence \\
\hline $\begin{array}{c}\text { Development of } \\
\text { spatial vision }\end{array}$ & $\begin{array}{c}\text { Geometry helps to develop spatial } \\
\text { vision }\end{array}$ & $32,24 \%$ \\
\hline $\begin{array}{l}\text { Relationship with } \\
\text { the world }\end{array}$ & $\begin{array}{c}\text { Geometry is everywhere in our } \\
\text { world }\end{array}$ & $28,95 \%$ \\
\hline $\begin{array}{c}\text { Solving everyday } \\
\text { problems }\end{array}$ & $\begin{array}{l}\text { Geometry helps children to solve } \\
\text { everyday problems. }\end{array}$ & $28,29 \%$ \\
\hline $\begin{array}{l}\text { Improving the } \\
\text { way of thinking }\end{array}$ & $\begin{array}{c}\text { Geometry improves children } \\
\text { capacity of reasoning }\end{array}$ & $11,84 \%$ \\
\hline Future studies & $\begin{array}{c}\text { Geometry is important for future } \\
\text { studies }\end{array}$ & $11,18 \%$ \\
\hline \multicolumn{3}{|c|}{ Other reasons } \\
\hline Label & Description & Occurrence \\
\hline Not important & $\begin{array}{l}\text { Geometry is unimportant in } \\
\text { children education. }\end{array}$ & $1,32 \%$ \\
\hline
\end{tabular}


As it can be seen, the most used reason to justify Geometry in Primary Education is that children should know how to identify the different geometric figures. The second most widely used justification was "spatial vision development". Of the sample, $1.3 \%$ of the students said that Geometry was not important for students.

The NCTM, in its Principles and Standards [1] stablishes that Geometry should capacitate students to 1) analyse geometric figures 2) develop math reasonings about geometric relations, 3) locate and describe spatial relations, 4) apply transformations to analyse math situations, and 5) use visualization, reasoning, and geometric modelling to solve problems. If we compare these directives with the ones given by the study, we appreciate that the point 1) is only partially covered, as the participants focused on the identification of geometric figures, rather than analysing them. The point 3) refers to the "Spatial vision" label, and the points 2) and 5) can be covered by the labels "Improving the way of thinking" and "Solving everyday problems". No participants used reasons related to geometric transformations (point 4).

We also see that the most frequent reasons were those of visual character (figures, spatial vision and relationship with the world) whereas the labels "Improved the way of thinking" and "Solving everyday problems" were less frequents. This is an indicative that the participants gave more weight to the visual aspects of Geometry than the reasoning and logic ones.

Figure 1 shows the occurrences of tags by sex. In order to determine whether the differences observed in terms of sex were statistically significant, Fisher's Exact Test was carried out for each label, obtaining no significant results in any case. In other words, there is no statistical evidence of differences in both genders in terms of adduced reasons for the importance of teaching Geometry in Primary Education.

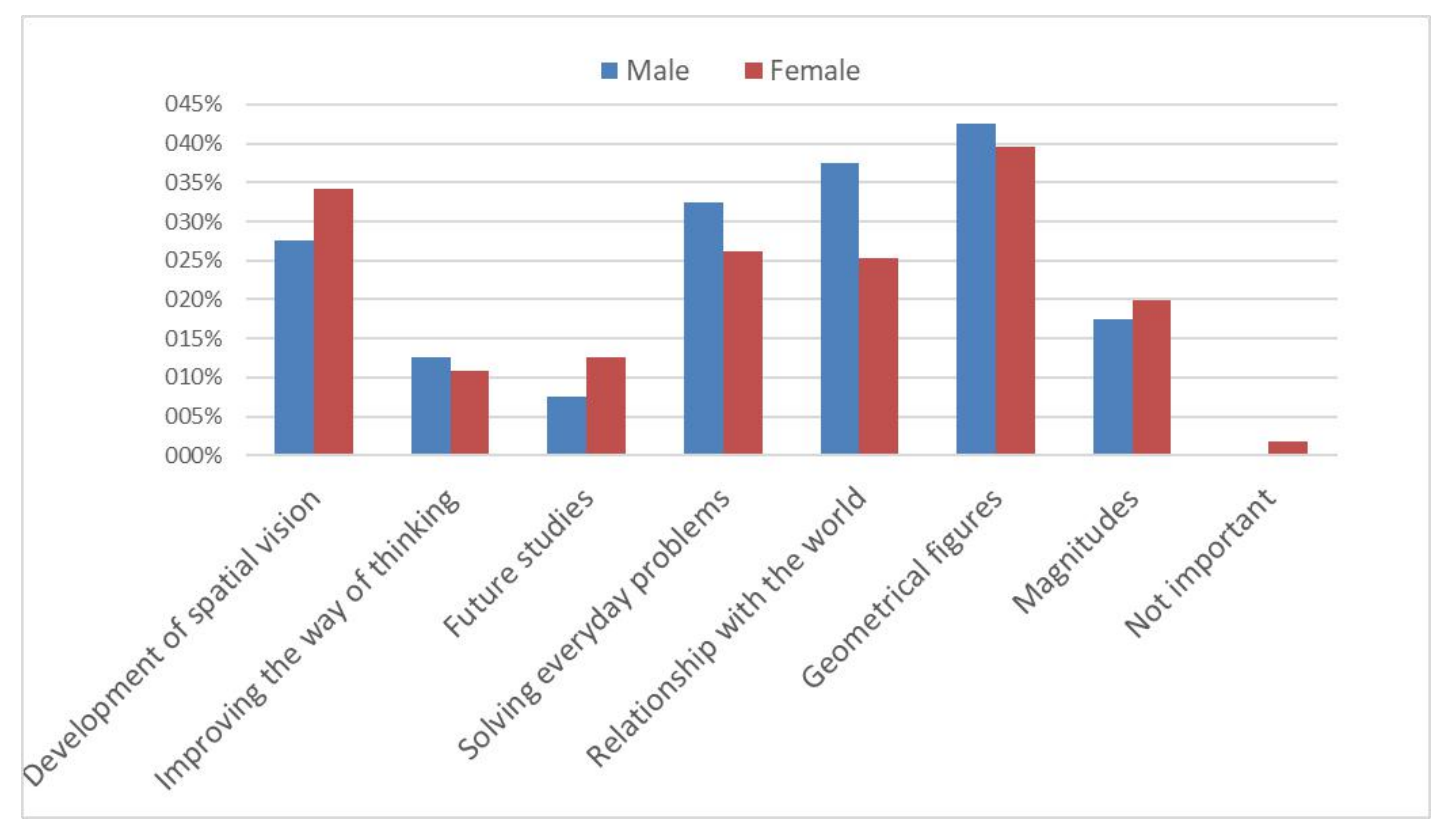

Figure 1. Reasons given about the importance of teaching Geometry in Primary Education, by gender.

\subsection{Math Anxiety}

Concerning the level of Math Anxiety observed, an average of 26.74 was obtained in the test scale, over a theoretical maximum value of 45 , which is slightly higher than the values of the population studied in [22]. Separating by genders an average score of 28.44 was obtained in women and 22.03 in men, a difference that matches multiple experiments performed earlier (for example, see [24]). The sample gives a Cronbach's Alpha of 0.853, representative of a good internal consistency.

The two factors obtained in the validation were considered [22], Anxiety related to the Learning of Mathematics (MLA) and Anxiety related to the Evaluation of Mathematics (MEA), with the basic descriptive statistics separated by gender in Table 2.

Table 2. Mean and Standard Deviation of MLA and MEA, by gender

\begin{tabular}{cccccccc}
\hline MLA & Male & Female & & MEA & Male & Female \\
\cline { 1 - 2 } \cline { 5 - 7 } Mean & 7,59 & 9,11 & & Mean & 12,39 & 16,08 \\
\cline { 1 - 2 } \cline { 5 - 7 } Standard Deviation & 2,22 & 2,96 & & Standard Deviation & 3,53 & 3,61 \\
\hline
\end{tabular}


The differences between men and women of both variables are statistically significant in position (median test) which is consistent with multiple studies like [17] or example. MLA also presents significant differences between genders in terms of dispersion, with a p-value of 0.003 in the Levene's Test, which means that female students tend to show more extreme values of anxiety about their mean than male do.

In both genders, Shapiro-Wilk Test rejected the normal distribution of anxieties, so that for the purposes of hypothesis testing, non-parametric tests were used.

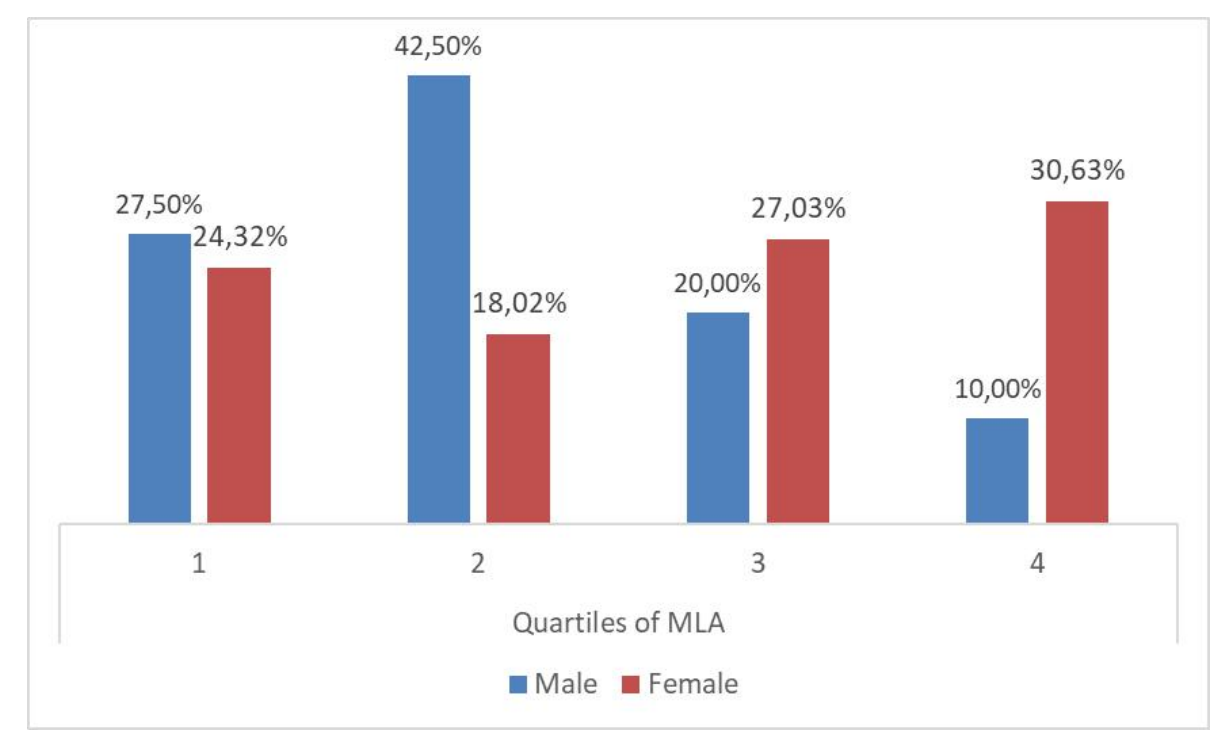

Figure 2. Distribution of men vs. distribution of women by MLA quartiles.

In Figure 2 the distribution of genders is represented, grouped by MLA quartiles of the whole sample. It is observed that in the first quartile the distribution of sexes is balanced, that is, the percentage of male students who have a level of mathematical learning anxiety in the first quartile is the same as that of female students. On the other hand, in the second quartile there is a clear majority of men, and in the third and last quartile there is a majority of women. The distribution of frequencies in the case of male students reaches their maximum in the second quartile, whereas in female students the opposite occurs. This may be indicative that women tend to be more willing to recognize anxiety than men [25], as women who should be in the second quartile would be self-classified in the third or fourth against men who would remain in the second or even be self-classified in the first, as they should be more reluctant to admit anxiety in general [26].

This effect does not appear in the distribution of genders grouped by MEA quartiles, shown in Figure 3, where the increasing or decreasing tendency respectively for female and male students is almost linear.

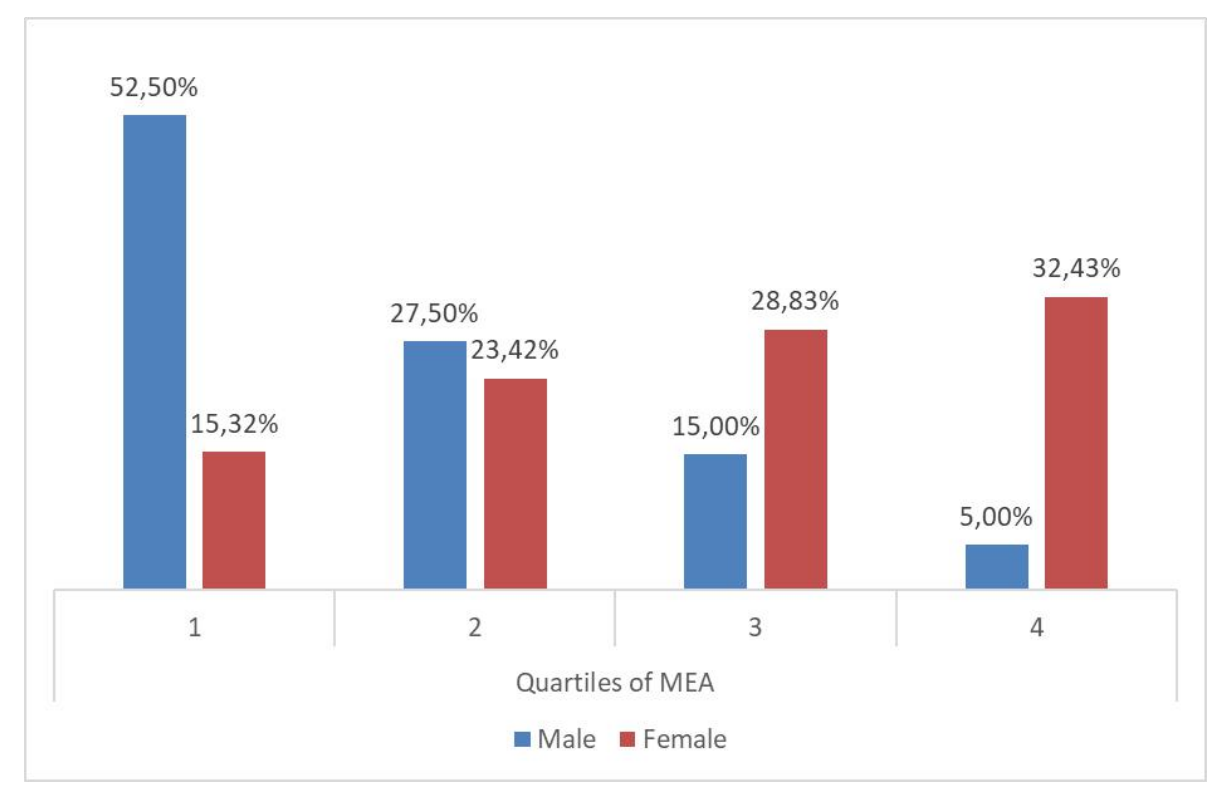

Figure 3. Distribution of men vs. distribution of women per quartile of MEA. 
On the other hand, it was studied whether the fact that the students gave some procedural or relational reason determined significant differences in their Math Anxiety. In Table 3, average levels of anxiety are shown according to whether in the answer to the questionnaire the pupil gave at least a reason of relational character or some procedural character. It is observed that those who gave at least one reason of relational character presented less average anxiety than the rest, while those who gave at least one of procedural character presented more average anxiety than those who did not, which may be an evidence that students who only consider the procedural aspects of Geometry tend to have more Math Anxiety.

Table 3. Average values of anxiety according to whether the pupil gave any reason of relational or procedural character.

\begin{tabular}{ccccc}
\hline & \multicolumn{2}{c}{$\begin{array}{c}\text { Math Learning } \\
\text { Anxiety }\end{array}$} & \multicolumn{2}{c}{$\begin{array}{c}\text { Math Evaluation } \\
\text { Anxiety }\end{array}$} \\
\cline { 2 - 5 } & NO & YES & NO & YES \\
\hline $\begin{array}{c}\text { A relational reason was } \\
\text { given }\end{array}$ & 9,13 & 8,47 & 15,76 & 15,00 \\
\hline $\begin{array}{c}\text { A procedural reason } \\
\text { was given }\end{array}$ & 8,21 & 8,98 & 14,59 & 15,70 \\
\hline
\end{tabular}

Table 4. p-values of Median and Mann-Whitney test to compare Math Anxiety levels if a relational or a procedural reason was given.

\begin{tabular}{|c|c|c|c|c|}
\hline & \multicolumn{2}{|r|}{ MLA } & \multicolumn{2}{|r|}{ MEA } \\
\hline & $\begin{array}{c}\text { Median } \\
\text { test }\end{array}$ & Mann-Whitney & $\begin{array}{c}\text { Median } \\
\text { test }\end{array}$ & Mann-Whitney \\
\hline $\begin{array}{l}\text { A relational } \\
\text { reason was } \\
\text { given }\end{array}$ & 0,120 & 0,160 & 0,798 & 0,392 \\
\hline $\begin{array}{c}\text { A } \\
\text { procedural } \\
\text { reason was } \\
\text { given }\end{array}$ & 0,056 & 0,091 & 0,361 & 0,098 \\
\hline
\end{tabular}

To check whether these differences are statistically significant, the median and Mann-Whitney U Tests were carried out, obtaining the results shown in Table 4 . It is observed that students who gave at least one procedural reason showed significant differences at a level 0.056 in the median of the Learning Anxiety of Mathematics. It is also observed that in general the p-values for MLA are smaller than for MEA, which can suggest that the MLA is a more related factor that MEA with the relational or procedural vision of the students. Also, low p-values may indicate that increasing the sample size should give statistically significant differences.

In Table 5 the average levels of Math Learning Anxiety and Math Evaluation anxiety are separated according to the reasons the students used to justify the importance of studying Geometry in Primary Education.

It should be noted that, in a purely descriptive approach to the Table 5, claiming relational reasons for the teaching of Geometry is related to a decrease in average anxiety in learning, whereas alleging procedural reasons gets the opposite effect. This may be an indicator that a more procedural view of Geometry (and perhaps other branches of Mathematics) may be related to higher levels of anxiety related to learning Mathematics in students, which is consistent with previous studies that conclude that students with more mathematical anxiety feel more comfortable using a procedural approach to the subject [20, 21].

By applying the median equality test, significant differences were obtained in Mathematics Learning Anxiety for "Thinking" and " Magnitudes" items, both with opposite effects over the MLA and MEA. Although the effects of the "Magnitudes" item over the MEA is not statistically significant, the median test gives a p-value of 0.161 , which should indicate that increasing the sample size could lead to reject the null hypothesis.

In Figure 4 we can appreciate the percentage of students who argued that Geometry favours their ability to reason and think, grouped by quartiles of Anxiety in Mathematical Learning (MLA) and Anxiety in the Evaluation of Mathematics (MEA). As anxiety levels increase, the percentage of students who used that reason to justify Geometry in Primary Education decreases. The differences in the Q3 and Q4 quartiles are not statistically significant. The chi-square test of homogeneity gave p-values of 0.032 and 0.016 respectively, so we can state that mathematical anxiety effectively (in its two forms) is related, at a statistical level, with the perception that students have about the usefulness of Geometry in the ability to reason and think of the student (no frequency with expected value less than 5 , so the tests are valid). The same study was replicated differentiating by genders and no statistically significant differences were found between male and female students, using the chi-squared test.

Table 5. Average levels of Math Anxiety by reasons alleged. With asterisk, statistically significant differences at $\mathrm{p}=0.05$.

\begin{tabular}{cccccccc}
\hline \multirow{2}{*}{ Type } & \multirow{2}{*}{ Labels } & \multicolumn{3}{c}{ Math Learn Anxiety } & \multicolumn{3}{c}{ Math Evaluation Anxiety } \\
\cline { 3 - 7 } & & NO & YES & DIFF. & NO & YES & DIFF. \\
\hline \multirow{2}{*}{ Procedural reasons } & Geometrical figures & 8,68 & 8,73 & 0,05 & 14,95 & 15,31 & 0,36 \\
\hline & Magnitudes & 8,49 & 9,57 & $1,07^{*}$ & 14,86 & 16,08 & 1,22 \\
\cline { 2 - 7 } & Development of spatial vision & 8,79 & 8,56 & $-0,22$ & 15,04 & 15,26 & 0,23 \\
\cline { 2 - 7 } & Relationship with the world & 8,78 & 8,55 & $-0,23$ & 15,23 & 14,80 & $-0,43$ \\
\cline { 2 - 7 } Relational reasons & Solving everyday problems & 8,78 & 8,54 & $-0,25$ & 15,27 & 14,69 & $-0,58$ \\
\cline { 2 - 7 } & Improving the way of thinking & 8,92 & 7,09 & $-1,83^{*}$ & 15,40 & 12,85 & $-2,55^{*}$ \\
\cline { 2 - 7 } & Future studies & 8,78 & 8,17 & $-0,61$ & 15,18 & 14,53 & $-0,65$ \\
\cline { 2 - 7 } & Geometry is unimportant in children education & 8,68 & 11,21 & 2,52 & 15,10 & 15,39 & 0,28 \\
\hline Other reasons & & & & & & &
\end{tabular}




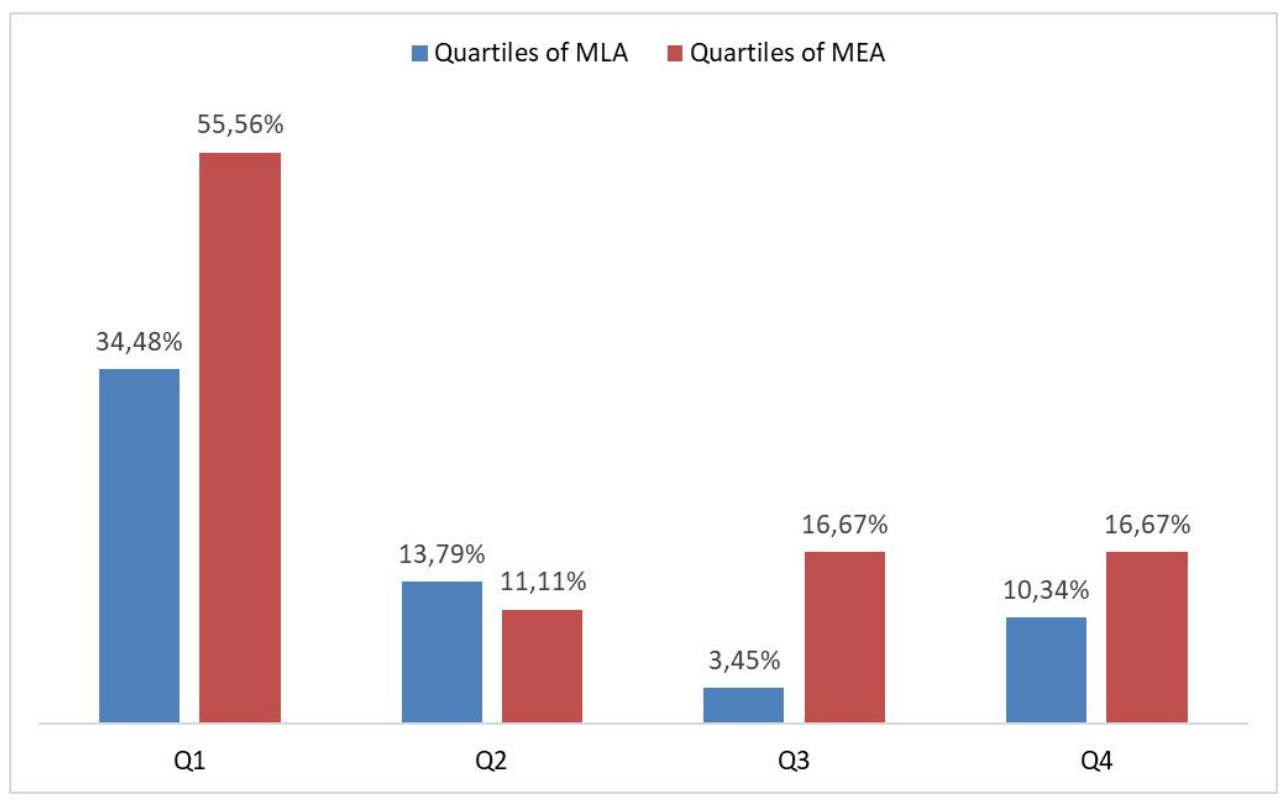

Figure 4. Distribution of students who alleged "Improving the way of thinking" as a reason to teach Geometry in Primary Education, grouped by quartiles of MLA and MEA.

Regarding the students who justified the importance of Geometry in Primary Education in relation to knowing the geometric figures (the item that was most observed), in Figure 5 it is observed that it does not relate to the levels of anxiety. That is, a participant of any quartile of both MLE and MEA tends to value in equal proportion the knowledge of the geometric figures as a reason for the teaching of Geometry in Primary Education. The chi-squared test of homogeneity gives a p-value of 0.537 (no frequency with expected value less than 5 , so the test is valid), without statistically significant evidence so that the opposite occurs. This leads to think that, although procedural and relational reasons seem to have opposite signs in their correlation with Math Anxiety, the strength of this correlation is not equal for all reasons.

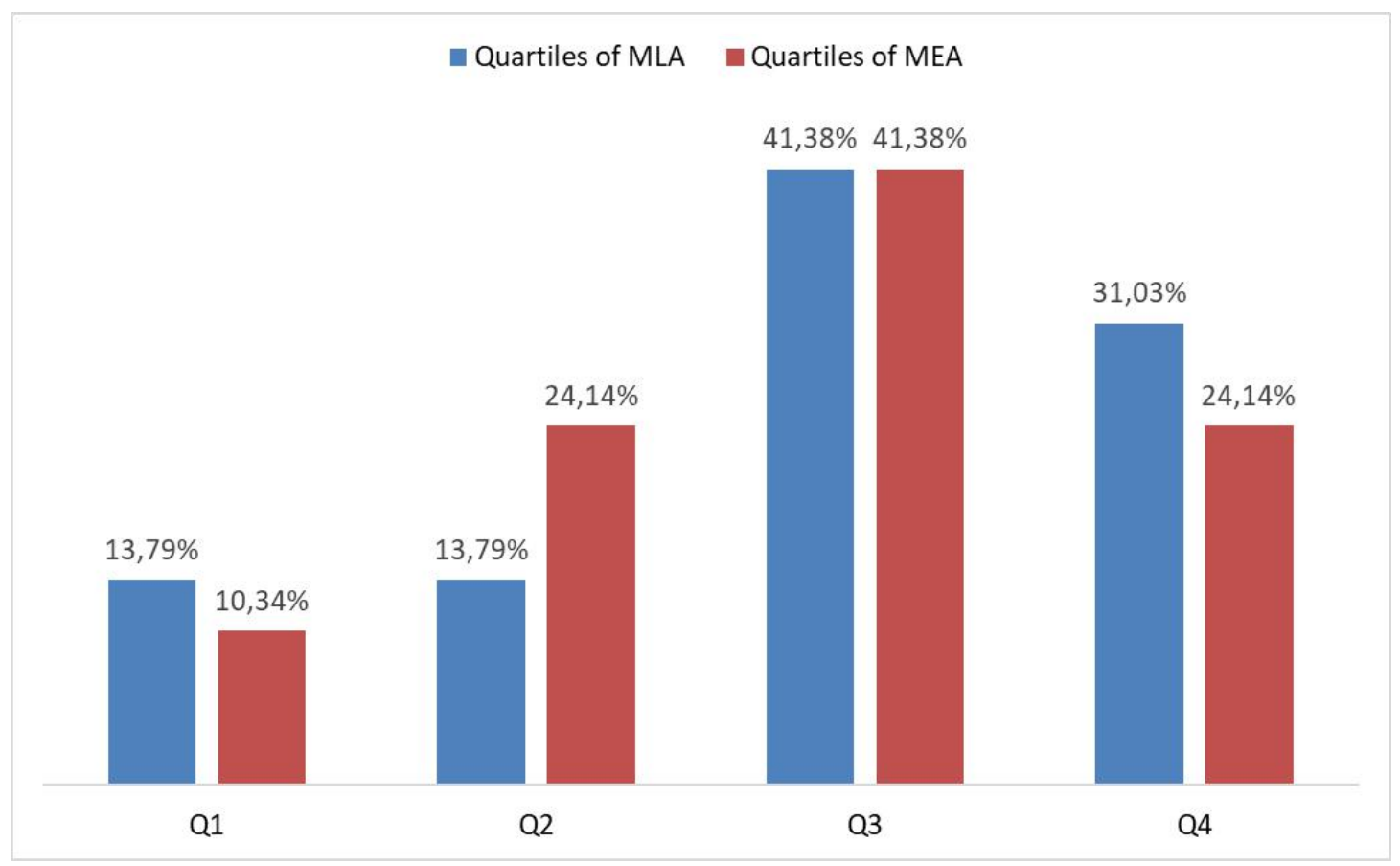

Figure 5. Distribution of students who alleged "Geometric figures" as a reason to teach Geometry in Primary Educations, grouped by quartiles of MLA and MEA. 


\section{Conclusions}

According to the results, prospective teachers studied used mostly reasons of visual character to justify Geometry teaching in Primary Education, as they identify Geometry with figures and spatial vision. In spite of transformations being one of the main concepts in teaching Geometry according to the NCTM, no participants referred to it, which denotes a clearly biased vision of Geometry.

Evidence has shown that a procedural approach to justify Geometry in Primary Education is related to higher levels of mathematical anxiety, specially the MLA factor, although not all the reasons had the same level of correlation.

Those students who stated that Geometry should be taught in Primary Education because it improves the ability to think and reason showed statistically significant evidence of lower levels of anxiety, both in learning and in evaluation of Math. Also, although the levels of anxiety have obvious differences between genres, there are no significative differences in the allegiance of reasons of relational or procedural nature to justify the teaching of Geometry in Primary Education.

This leads to consider that emotional factors in future teachers should be considered as they can influence in their didactic strategies. A teacher who deeply thinks that Geometry is important only because students must know how to calculate distances or areas will tend to adopt a more procedural, non-relational approach to his classes, no matter what strategies has been taught on the University. Thus, a teacher training program should consider not only math skills and familiarity with didactic strategies, but also proper beliefs and attitudes towards Math itself.

Some variables could not be controlled at the time of data collection, like the academic trajectory of each participant, the style of teaching given, or even personal experiences with the matter, which should be considered in future expansions of this study.

\section{REFERENCES}

[1] NCTM. (2000). Principles and standards for school mathematics (Vol. 1). National Council of Teachers of Mathematics.

[2] Ministerio de Educación y Ciencia. Real Decreto 126/2014, de 28 de febrero, por el que se establece el currículo básico de la Educación Primaria. (2014).

[3] Barrantes, M., \& Blanco, L. J. (2004). Recuerdos, expectativas y concepciones de los estudiantes para maestro sobre la geometría escolar. Enseñanza de las ciencias: revista de investigación y experiencias didácticas, 22(2), 241-250.

[4] Barrantes, M., \& Blanco, L. J. (2006). A Study of
Prospective Primary Teachers' Conceptions of Teaching And Learning School Geometry. Journal of Mathematics Teacher Education, 9(5), 411-436. https://doi.org/10.1007/s10857-006-9016-6

[5] Casas-Rosal, J. C., Villarraga Rico, M., Maz-Machado, A., Castro Carvajal, D., \& León-Mantero, C. (2019). Profesores en formación de la Universidad del Tolima: un análisis de sus actitudes hacia la Estadística. Matemáticas, Educación y Sociedad, 2(3), 9-19.

[6] Gil, N., Blanco, L., \& Guerrero, E. (2006). El dominio afectivo en el aprendizaje matemático. International Electronic Journal of Mathematics Education, 1(1), 16-32.

[7] Gómez-Chacón, I. M. (2002). Afecto y aprendizaje matemático: causas y consecuencias de la interacción emocional. Reflexiones sobre el pasado, presente y futuro de las Matemáticas, 197-227.

[8] Hart, L. E., \& Walker, J. (1993). The role of affect in teaching and learning mathematics. Research ideas for the classroom: Middle grades mathematics, 22-38.

[9] Hill, D., \& Bilgin, A. A. (2018). Pre-Service Primary Teachers' Attitudes towards Mathematics in an Australian University. Creative Education, 9(04), 597-614.

[10] Richardson, F. C., \& Suinn, R. M. (1972). The mathematics anxiety rating scale: psychometric data. Journal of counseling Psychology, 19(6), 551.

[11] Fennema, E., \& Sherman, J. A. (1976). Fennema-Sherman mathematics attitudes scales: Instruments designed to measure attitudes toward the learning of mathematics by females and males. Journal for research in Mathematics Education, 7(5), 324-326.

[12] OECD (2012). PISA 2012 results in focus. Secretary-General of the OECD, Available from: http://www.oecd.org/pisa/keyfindings/pisa-2012-results-ov erview.pdf.

[13] Timmerman, H. L., Toll, S. W. M., \& Van Luit, J. E. (2017). The relation between math self-concept, test and math anxiety, achievement motivation and math achievement in 12 to 14-year- old typically developing adolescents. Psychology, Society, \& Education, 9(1), 89. https://doi.org/10.25115/psye.v9i1.465

[14] Hidalgo, S., Maroto, A., Ortega, T., \& Palacios, A. (2013). Atribuciones de Afectividad hacia las Matemáticas. UNIÓN. Revista Iberoamericana de Educación Matemática, (35), 93-113.

[15] Schillinger, F. L., Vogel, S. E., Diedrich, J., \& Grabner, R. H. (2018). Math anxiety, intelligence, and performance in mathematics: Insights from the German adaptation of the Abbreviated Math Anxiety Scale (AMAS-G). Learning and Individual Differences, 61, 109-119.

[16] Monge, I. C. D., González, J. E., \& Fonseca, J. (2017). Ansiedad matemática en estudiantes universitarios de Costa Rica y su relación con el rendimiento académico y variables sociodemográficas. Propósitos y representaciones, 5(1), 275-324.

[17] Pérez-Tyteca, P., Martínez, E. C., Romero, L. R., \& Martínez, E. C. (2011). Ansiedad matemática, género y ramas de conocimiento en alumnos universitarios. Enseñanza de las ciencias: revista de investigación y 
experiencias didácticas, 29(2), 237-250.

[18] Beilock, S. L., Gunderson, E. A., Ramirez, G., \& Levine, S. C. (2010). Female teachers' math anxiety affects girls' math achievement. Proceedings of the National Academy of Sciences, 107(5), 1860-1863.

[19] Bush, W. S. (1989). Mathematics Anxiety in Upper Elementary School Teachers. School Science and $\begin{array}{ll}\text { Mathematics, } & 89(6),\end{array}$ https://doi.org/10.1111/j.1949-8594.1989.tb1 1952.

[20] Clute, P. S. (1984). Mathematics Anxiety, Instructional Method, and Achievement in a Survey Course in College Mathematics. Journal for Research in Mathematics Education, 15(1), 50. https://doi.org/10.2307/748987

[21] Norwood, K. S. (1994). The Effect of Instructional Approach on Mathematics Anxiety and Achievement. School Science and Mathematics, 94(5), 248-254. https://doi.org/10.1111/j.1949-8594.1994.tb15665.

[22] Hopko, D. R., Mahadevan, R., Bare, R. L., \& Hunt, M. K. (2003). The Abbreviated Math Anxiety Scale (AMAS): Construction, Validity, and Reliability. Assessment, 10(2), 178-182. https://doi.org/10.1177/1073191103010002008

[23] Skemp, R. R. (2012). The psychology of learning mathematics: Expanded American edition. Routledge.

[24] Devine, A., Fawcett, K., Szücs, D., \& Dowker, A. (2012). Gender differences in mathematics anxiety and the relation to mathematics performance while controlling for test anxiety. Behavioral and Brain Functions, 8(1), 33. https://doi.org/10.1186/1744-9081-8-33

[25] Reyes, L. H. (1984). Affective Variables and Mathematics Education. The Elementary School Journal, 84(5), 558-581. https://doi.org/10.1086/461384

[26] Mousavi, M., Haghshenas, H., \& Alishahi, M. (2008). Effect of gender, school performance and school type on test anxiety among Iranian adolescents. 